\title{
Analysis of genotype-environment interaction and yield stability of Thai upland rice (Oryza sativa L.) genotypes using AMMI model
}

\author{
Shams Shaila Islam ${ }^{1,2}$, Jakarat Anothai ${ }^{1}$, Charassri Nualsri ${ }^{1}$, Watcharin Soonsuwon ${ }^{1^{*}}$ \\ ${ }^{1}$ Department of Plant Science, Faculty of Natural Resources, Prince of Songkla University, Hat Yai, Songkhla 90112, \\ Thailand \\ ${ }^{2}$ Department of Agronomy, Faculty of Agriculture, Hajee Mohammad Danesh Science and Technology University, \\ Dinajpur 5200, Bangladesh
}

*Corresponding author: watcharin.s@psu.ac.th

\begin{abstract}
Genotype-environment interaction and stability analysis has been important for plant breeders and plays a vital role in identifying genotypes that are stable or unstable in a given environment. The experiments in this research were conducted to determine the effects of genotype, environment and genotype-environment interaction on grain yield using the AMMI statistical model, and to recognize the most stable rice genotypes among ten genotypes in southern Thailand's provinces of environments in Songkhla, Satun and Phatthalung. Highly significant differences were shown from the combined analysis for environments with grain yields, revealing that environments were different and indicated change ability between the genotypes and their interactions. The average grain yield assessment of the tested genotypes was around the environments where genotype G8 (Nahng Kian) had the highest grain yield $6234.11 \mathrm{~kg} / \mathrm{ha}$. AMMI biplot of the Interaction Principal Component Analysis (IPCA) scores visualized $90.7 \%$ for IPCA1 and $9.3 \%$ for IPCA2 with the genotypes and environments for grain yield. In the AMMI stability value method, G8 (Nahng Kian) was the most stable genotype followed by the genotypes G2 (Mai Tahk) and G10 (Hawm Jet Ban) Songkhla, Satun and Phatthalung environments.
\end{abstract}

Keywords: AMMI, environment, genotypes, GxE interaction, upland rice, yield stability.

Abbreviations: AMMI_additive main effect and multiplicative interaction; IPCA_interaction principal component analysis; ASV_AMMI stability value; ANOVA_analysis of variance; df_degrees of freedom; CV\%_coefficient of variation; TSS_total sum of squares.

Introduction

Rice (Oryza sativa L.) is an essential staple cereal crop nourishing more than half of the world's populations making up 50 to $80 \%$ of regular caloric consumption (Amirjani, 2011). Bridhikitti and Overcamp (2011), mentioned that Japonica, Javanica and Indica are subspecies, and that irrigated, rainfed lowland, deep water, and upland comprise the various cultivation ecosystems. Upland rice is grown in rainfed, naturally well-drained soils without surface water accumulation or a phreatic water supply, and is also usually not bunded. Messina et al. (2009) reported that grain yield is contingent on genotype and, environment, in addition to management practices. Given similar management situations, differences in grain yield exist mainly due to effects of genotype and environment as reported by Dingkuhn et al. (2006). Combining these double descriptive variables provides ideas for recognizing the genotype most appropriate for a given the environment.

Genotype and environment interaction (GXE) imitate the diverse reactions of the genotypes to different environmental conditions, i.e., one genotype under certain conditions is not the best genotype for other conditions. They are influenced by the environment. Hence, the G×E interaction cannot represent all inherent possibilities under certain which associated toward environmental conditions, and makes recommendations of genotypes to the plant breeder challenging (Arciniegas-Alarcn et al., 2010). According to Rodrigues et al. (2014), different response of genotypes across environments (location-yearcombinations) is often normal in multi-environmental trials and is known as GXE interaction. It governs the identification of stable genotypes suitable for an environment, as well as of genotypes with a general behaviour that are suitable across several environments (Annichiarico and Perenzin, 1996).

A strong $G \times E$ interaction slows down selection and identification of genotypes, and makes recommendations difficult. To analyze G×E interaction and phenotypic stability, several methods have been proposed, specifically univariate and multivariate stability statistics methods. A combined analysis of variance can quantify the interactions and describe 
the main effects (Genotype and Environment) reported by (Lin et al., 1986). Univariate is used of GXE interaction. Among multivariate approaches, AMMI analysis has been extensively applied in statistical analyses because it captures a large portion of the GXE interaction sum of squares, and clearly separates main and interactive effects. It also often provides meaningful interpretation of records which supports a breeding program such as genotype stability which represents agronomic investigations through different types of chances. In addition, the model affords agriculturally evocative clarification of high productivity records and is increasingly well adapted to a given agronomic region, through the purpose of regionalized endorsement, plus collection of check locations (Ebdon and Gauch, 2013; Rodrigues et al., 2014).

According to Gauch et al. (2008), the AMMI model combines ANOVA for the main genotype and environmental effects with principal component analysis of GXE. Consequently, based on the AMMI model, the AMMI stability value (ASV) has been used (Purchase et al., 2000). Formerly, the Principal Component Analysis (PCA), that affords a different model, is useful to investigate the cumulative consequences since the additive ANOVA model. According to Thillainathan and Fernandez (2001), the biplot display of PCA scores plotted against each other provides visual inspection and interaction components. Integrating biplot display and genotypic stability statistics enables genotypes to be grouped based on similarity of performance across diverse environments. Application of the AMMI model for yield trials have taken place regularly throughout the previous two eras, and there have been numerous new assessment apprenticeships (Gauch et al., 2008; Yang et al., 2009; Rodrigues et al., 2014).

The AMMI result is gaining popularity and has been widely preferred in recent years for breeding programs, judgments such as definite and extensive alterations, as well as for the assortment of the environments (Manrique and Hermann, 2002; Gruneberg et al., 2005). Hence, the objectives of this research were to 1) estimate the extension of genotype, environment and GXE interactions for grain yield, 2) evaluate rice genotypes on behalf of their yield performance in particular environments, and 3) select genotypes in terms of their stability for definite region production depending on their grain yield performance in particular environments.

\section{Results and Discussion}

\section{Climatic differences analysis}

According to Eberhart and Russell (1966), high variations occurring in this result were caused by several factors such as soil properties, total phosphorus, available phosphorus, as well as rainfall. Changeable environmental features such as relative humidity and rainfall through a single situation can underscore dissimilarity of genotypes in relation to environment across locations. For the different location trials, the location in which the field trials were undertaken showed geographical and environmental dissimilarities. Therefore, an enormous influence from the environment was expected. Consequently, tested genotypes in different environments differed in changeable environmental conditions, which suggests that a proper method intended for choosing genotypes exists. From Table 1, it can be seen that the Phatthalung environment has very low percentage of total phosphorus $(121.92 \mathrm{mg} / \mathrm{kg}$ ), available phosphorus $(2.95 \mathrm{mg} / \mathrm{kg})$, available Ca $(65.90 \mathrm{mg} / \mathrm{kg})$, available Fe $(162.56 \mathrm{mg} / \mathrm{kg})$, the lowest annually average rainfall $(575 \mathrm{~mm})$ and the medium humidity (85\%). In comparison, Satun environment has total phosphorus of $207.42 \mathrm{mg} / \mathrm{kg}$, available phosphorus of $10.84 \mathrm{mg} / \mathrm{kg}$, and available Fe of $353.16 \mathrm{mg} / \mathrm{kg}$ with relative humidity (81\%). The Songkhla environment has available $\mathrm{K}$ of $33.73 \mathrm{mg} / \mathrm{kg}$ and the annually average highest rainfall $(583 \mathrm{~mm})$.

\section{Single analysis}

From Table 2, single analysis of variance revealed that genotype with grain yield for the Satun and Phatthalung environments showed significant differences, indicating differential performances of genotypes over these two environments. Whereas Songkhla had no significant difference for genotype. This is due to more coefficient of variation values (27.72\%) for the Songkhla environment.

\section{Combined analysis}

Table 3 combines ANOVA of 10 genotypes in three environments (Satun, Phatthalung and Songkhla) showing highly significant differences for environments while no significant differences for genotypes and GXE interactions. The significant differences that $A M M I$ analysis identifies among genotypes, environments and GXE interaction, and indicates that there are highly significant differences among environments and that each environment has a strong effect on genotypes and GXE interactions, which help in selecting high yielding and stable genotypes in each environment. The genotypes and G×E interaction had no significant differences in grain yield in this combined analysis because there are very high mean squares of pooled error. The significance of $\mathrm{G} \times \mathrm{E}$ interaction indicates distinct genotypes in each location. This suggests the necessity to examine patterns of adaptability of genotype across each location. These findings were also reported by Falconer and Mackay (1996). The highly significant differences for the environment and G×E interaction designate high differential behaviour (Yaghotipoor and Farshadfar, 2007).

\section{AMMI analysis}

According to Gauch (1988), AMMI is an applicable model in the preliminary arithmetical study of yield trials as it supports different logical instrument to identify other models. AMMI helps to make good plan for predicting new locations and new year. Freeman (1990) stated that the AMMI model has the capability of overall fitting and place no limitations on the multiplicative term, which results in an acceptable minimum mean square. The IPCA scores of genotypes and environments are plotted against their respective mean values in the AMMI model 1 biplot, where the average productivity of the genotypes, environments and their interactions for all possible genotype-environment combinations visualize among them. 
The AMMI model is the recommended design for three key determinations. Firstly, the model identifies additional models; then illuminates $\mathrm{G} \times \mathrm{E}$ interaction and summarizes the extension and interactions of $G$ and $E$ (Crossa, 1990). It is evident from Table 4 for grain yield, 10 genotypes exposed $82.86 \%$ of total sum of squares is attributed to environmental effects, $1.31 \%$ to genotypic effects, and $2.44 \%$ to $\mathrm{G} \times \mathrm{E}$ interaction effects while IPCA1 accounted for $90.7 \%$, and IPCA2 accounted for only $9.3 \%$ of variation from GxE interaction. Therefore, the AMMI1 biplot gives the best model, with a fit of IPCA1 accounting for $90.7 \%$ of the total treatment variation in GXE data through grain yield (Fig 1). Large significant mean squares attributable to environments indicate large differences in the influence of environments i.e., environments are so diverse they cause the greatest variation on GXE interaction. Environments accounted for the largest proportion followed by G×E interactions and genotypes, as reported by Naveed and Nadeem (2007), and is about 41 times higher in comparison with genotypes and GXE interaction for grain yield on the productivity of genotypes. The $\mathrm{G} \times \mathrm{E}$ interaction sum of squares is much less for grain yield.

Less GXE interaction greatly sped up the selection process rapidly and made genotype recommendations easier. It also destroyed the high stable yields that are appropriate for yield breeders and growers, owing to its inherent configuration, and yields are greater which indicates that environments devour strong effects on the presentation of the genotypes (Zulqarnain et al.,2017). The significant contribution of G×E interaction towards grain yield variation suggests differential responses of genotypes to different environments. The partitioning of the total sum of squares indicates that the environmental effect is a leading source of variation followed by the genotype and GXE interaction, which suggests the presence of different genotypes suitable to different environments (Mohammadi et al., 2007). Highly significant G×E interaction reduces responses to a selection of superior genotypes (Flores et al., 1998). Hence, it is appropriate to assess yield stability under different environments and identify genotypes with a specific or broad adaptation. This is consistent with the findings of Islam et al. (2014). The existence of $\mathrm{G} \times \mathrm{E}$ interaction is visibly confirmed through the AMMI 1 model. The interaction is separated between the IPCAs, and the two IPCAs together accounted for $100 \%$ of the overall GXE interactions for grain yield: $90.7 \%$ from IPCA1 and 9.3\% from IPCA2. However, $10.73 \%$ was pooled error or residual noise and was not interpretable, thus discarded (Purchase et al., 1997). Table 4 indicates that the AMMI model is good fit with the data, and that the model can predict accuracy using the IPCA (Beya et al., 2008).

The AMMI1 biplot analysis using IPCA1 and mean grain yield data from Table 4 allows visual interpretation of $G \times E$ interactions and genotype recommendation for multienvironments (Fig. 1). Here the " 0 " is a perpendicular line. The display shows, from the center of the perpendicular line, that genotypes with environments on the right side (both upper and lower) always bear highest mean values of grain yield. The upper right quadrant, contains more high mean grain yield values than those in the lower right quadrant, which have medium mean grain yield values. Those on the left side, have the lowest mean grain yield values. Taking the performance of the perpendicular line as standard, genotypes with high mean values and positive interaction with IPCA1 are in the Satun environment. As a result, among the ten genotypes G8, G9, G10, G3, G7 and G4, are generally high yielding with the highest mean values $(6234.11,6115.56,6043.44,5893.44$, 5854.78 and $5268.22 \mathrm{~kg} / \mathrm{ha}$, respectively) in the Satun environment. After that G1, G2, G5 and G6 (5546.56, 5342.89, 6115.56 and $5831.22 \mathrm{~kg} / \mathrm{ha}$, respectively) are in the Songkhla environment, and are generally lower yielding than the genotypes suited to the Satun environment. In contrast, Phatthalung is the poorest environment among the three, as shown on left side of the perpendicular line, and bore no best suited genotype. The Satun and Songkhla environments are on the right side of the vertical axis, indicating rich environments, whereas the Phatthalung environment is generally the poorest environment. Thus, the AMMI biplot shows that the studied genotypes differed from each other not only in their interactive effects but also in their mean grain yield values.

\section{IPCA interactions}

The AMMI biplot provides a visual expression of the relationships between the IPCA1 and IPCA2 with the mean of genotypes and environments. According to Alberts (2004), Principal Component Analysis is a multivariate technique that recognizes figure arrangements in addition to correspondences and differences between the variables established and arranged in a consecration procedure of multivariate systems. Table 5 shows IPCA1 and IPCA2 scores that characterize the interaction of a genotype across environments as well as relationships between genotypes and environments. According to Yan and Hunt (2001) and Mohammadi et al. (2007), a genotype with a positive IPCA score in several environments must neutralize negative interactions in other environments. Hence, these scores exhibit an unequal genotype reaction to the environment. Nevertheless, both positive and negative signs, as well as genotypes and environments using large IPCA scores, have strong large interactions and are stable. However, genotypes with IPCA1 and IPCA2 scores at zero or close to zero have little interaction across environments, indicating that they all perform well in these environments and are stable. Conversely, genotypes with negative IPCA1 and IPCA2 values had no interaction across environments (Crossa, 1990). All these are below average yields. Similarly, those genotypes have zero scores on the IPCA1, indicating that they are less influenced by the environments. On the other hand, the genotypes list above usually yield and IPCA1 score near zero, as they are accustomed to stable environments and are general adapted to all the environments. For grain yield, the biplot shows G8 had the highest mean value $(6234.11 \mathrm{~kg} / \mathrm{ha})$, followed by G9 with $6115.56 \mathrm{~kg} / \mathrm{ha}$ and G5 with $6115.56 \mathrm{~kg} / \mathrm{ha}$. These were all in Satun. The maximum mean value was $8425.60 \mathrm{~kg} / \mathrm{ha}$ and the interactions were strong. Among the experiments, for grain yield, G3, and the environment, Phatthalung was the most unstable and discriminate. Related symbols of the IPCA1 score on behalf of similar genotypes as well as environment indicates positive association and 
Table 1. Soil property and weather condition before land preparation during the growing season.

\begin{tabular}{|c|c|c|c|}
\hline $\begin{array}{l}\text { Samples } \\
\text { Details }\end{array}$ & Satun & Phatthalung & Songkhla \\
\hline \multicolumn{4}{|l|}{ Soil properties $(0-30 \mathrm{~cm})$} \\
\hline Total N (\%) & 0.08 & 0.09 & 0.08 \\
\hline Organic matter (\%) & 1.9 & 1.9 & 1.9 \\
\hline Organic Carbon (\%) & 1.1 & 0.9 & 1.1 \\
\hline Total P (mg/kg) & 207.42 & 121.92 & 165.92 \\
\hline Available P (Bray II method, mg/kg) & 10.84 & 2.95 & 6.38 \\
\hline Available $\mathrm{K}\left(\mathrm{NH}_{4} \mathrm{OAc}\right.$ extract, mg/kg) & 26.75 & 28.10 & 33.73 \\
\hline Available $\mathrm{Ca}\left(\mathrm{NH}_{4} \mathrm{OAc}\right.$ extract, $\left.\mathrm{mg} / \mathrm{kg}\right)$ & 99.74 & 65.90 & 90.63 \\
\hline Available Fe DTPA extract $(\mathrm{mg} / \mathrm{kg})$ & 353.16 & 162.56 & 238.61 \\
\hline Cation Exchange Capacity (meq/100g soil) & 4.09 & 4.05 & 3.13 \\
\hline $\mathrm{pH}\left(1: 5 \mathrm{H}_{2} \mathrm{O}\right)$ & 5.09 & 4.89 & 4.87 \\
\hline $\mathrm{Ec}(\mu \mathrm{S} / \mathrm{cm})$ & 25.90 & 18.43 & 21.30 \\
\hline \multicolumn{4}{|l|}{ Weather properties } \\
\hline$\overline{\text { Max_temp }\left({ }^{0} \mathrm{c}\right)}$ & 36 & 35 & 35 \\
\hline Min_temp $\left({ }^{0} \mathrm{c}\right)$ & 24 & 25 & 26 \\
\hline Annually average rainfall (mm) & 580 & 575 & 583 \\
\hline Humidity (\%) & 81 & 85 & 87 \\
\hline
\end{tabular}

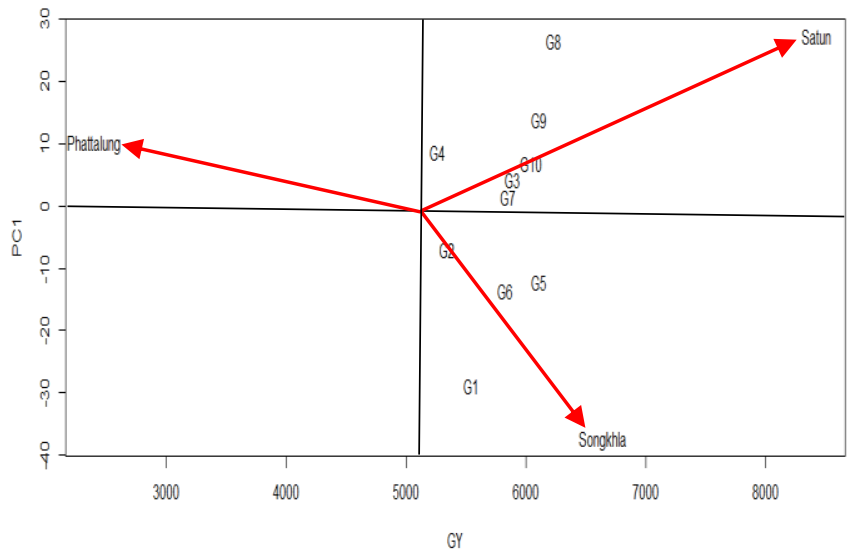

Fig 1. AMMI 1 biplot using IPCA1 and mean grain yield data for ten Thai genotypes in three environments.

Table 2. Single analysis of variance for grain yield of Thai upland rice genotypes.

\begin{tabular}{lcccc}
\hline \multirow{2}{*}{ Source } & df & \multicolumn{3}{c}{ Mean squares for Grain Yield } \\
\cline { 3 - 4 } Replication & 2 & $7159306^{* *}$ & Phatthalung & Songkhla \\
Genotype & 9 & $1507255^{*}$ & $1202650^{* *}$ & $848063^{\text {ns }}$ \\
Error & 18 & 594415 & $400517^{*}$ & $981513^{\text {ns }}$ \\
\hline CV (\%) & & 9.15 & 145121 & 3392696 \\
\hline *and** & & 15.90 & 27.72
\end{tabular}




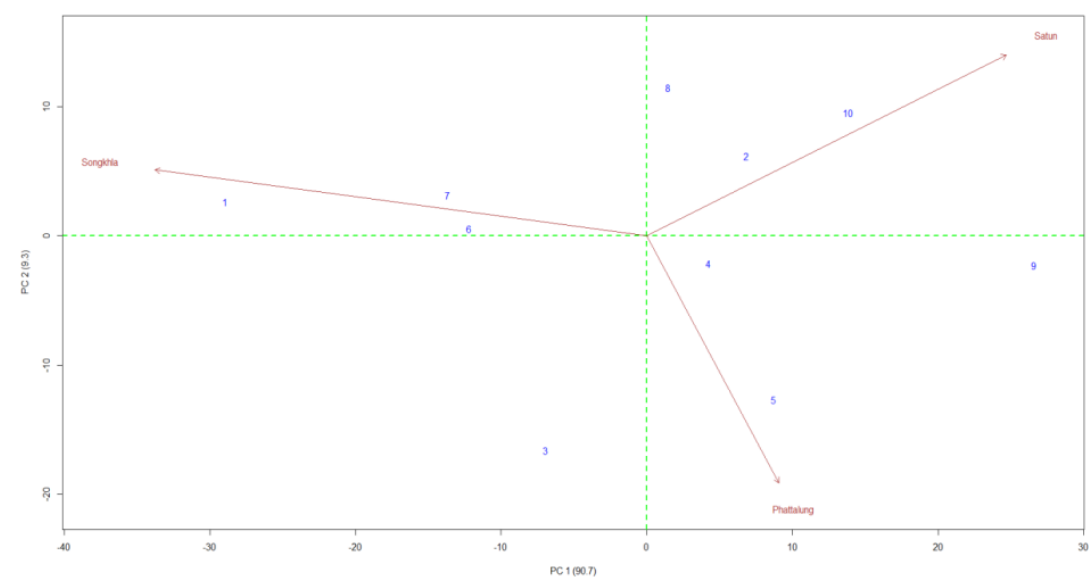

Fig 2. AMMI 2 biplot using (IPCA1 and IPCA2) scores data for grain yield with ten Thai genotypes in three environments.

Table 3. Mean squares of analysis of variance (ANOVA) for grain yield of 10 Thai upland rice genotypes across 3 locations.

\begin{tabular}{lll}
\hline Source of variation & df & Mean squares for Grain Yield \\
\hline Environment (E) & 2 & $287119472^{* *}$ \\
Replication within E & 6 & 3070006 \\
Genotype(G) & 9 & $1009507^{\text {ns }}$ \\
G×E & 18 & $939889^{\text {ns }}$ \\
Pooled error & 54 & 1377744 \\
\hline C.V. (\%) & & 20.15 \\
\hline${ }^{* *}$ indicates statistical significance at 1\% level probability and ns indicates non-significance.
\end{tabular}

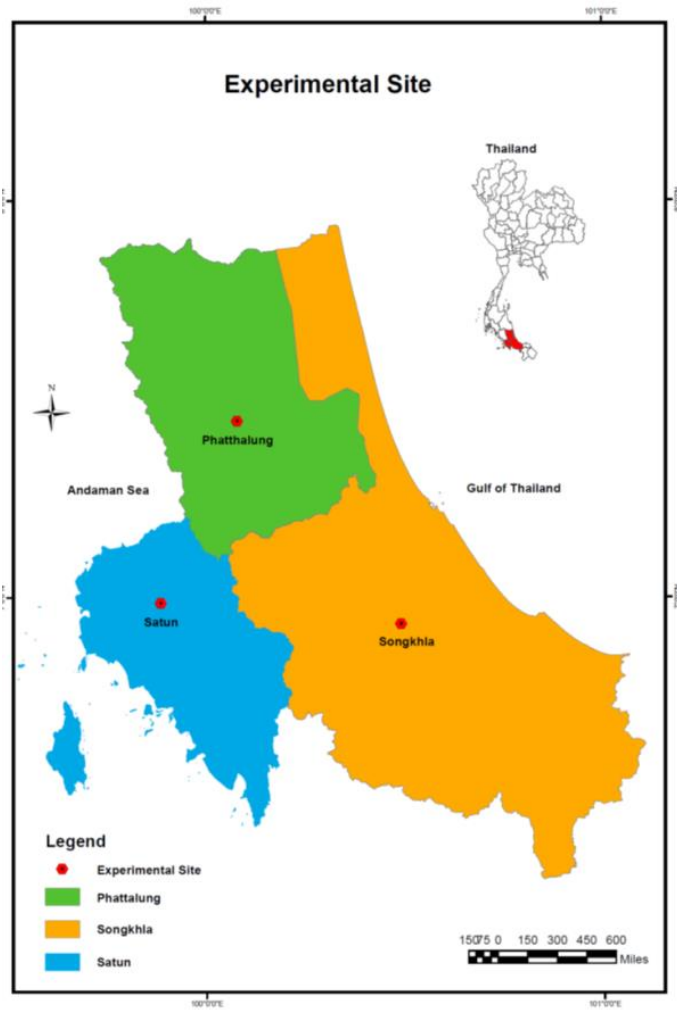

Fig 3. Map of three experimental sites. 
Table 4. AMMI analysis of grain yield in ten Thai upland rice genotypes over 3 locations.

\begin{tabular}{lllll}
\hline Source of variation & $\mathrm{df}$ & Total Sum of squares & Explained TSS (\%) & Percent of IPCA \\
\hline Environment(E) & 2 & 574238944 & 82.86 & 2.66 \\
Replication within E & 6 & 18420038 & 1.31 & 90.7 \\
Genotype(G) & 9 & 9085564 & 2.44 & 9.3 \\
G x E & 18 & 16917998 & - & - \\
IPCA1 & 10 & 15338587 & 10.73 & \\
IPCA2 & 8 & 1579411 & & \\
Pooled error & 54 & 74398169 & 693060713 & \\
Total & 87 & &
\end{tabular}

Table 5. AMMI analysis showing means with IPCA1, and IPCA2 scores of grain yield for 10 Thai upland rice genotypes grown in 3 locations.

\begin{tabular}{lllll}
\hline \multirow{2}{*}{ Genotype } & \multicolumn{4}{c}{ Grain Yield } \\
\cline { 2 - 4 } & Mean (kg/ha) & IPCA1 & IPCA2 & ASV \\
\hline G1 & 5546.56 & -28.93 & 2.65 & 27.25 \\
G2 & 5342.89 & 4.24 & 2.11 & 13.39 \\
G3 & 5893.44 & -6.93 & -16.60 & 90.19 \\
G4 & 5268.22 & 8.73 & -12.68 & 30.00 \\
G5 & 6115.56 & 12.18 & -0.55 & 37.97 \\
G6 & 5831.22 & -13.68 & 3.19 & 42.74 \\
G7 & 5854.78 & -26.58 & 2.26 & 82.86 \\
G8 & 6234.11 & 1.49 & 11.51 & 12.40 \\
G9 & 6115.56 & 13.83 & -9.55 & 44.15 \\
G10 & 6043.44 & 6.85 & 6.20 & 22.24 \\
Phatthalung & 2403.53 & 10.08 & -21.24 & 37.91 \\
Satun & 8425.60 & 27.43 & 15.56 & 86.89 \\
Songkhla & 6644.60 & -37.51 & 5.68 & 117.03 \\
\hline
\end{tabular}

Table 6. Details of ten popular Thai upland rice genotypes in different provinces in Thailand.

\begin{tabular}{lll}
\hline SL & Name of the genotypes & Collection site (Province) \\
\hline G1 & Dawk Pa-yawm (white rice) & Phatthalung \\
G2 & Mai Tahk (white rice) & Songkhla \\
G3 & Bow Leb Nahng (white rice) & Satun \\
G4 & Dawk Kha (red rice) & Krabi \\
G5 & Dawk Kahm (red rice) & Chumphon \\
G6 & Khao Trai (white rice) & Krabi \\
G7 & Nual Hawm (white rice) & Songkhla \\
G8 & Nahng Kian (white rice) & Chumphon \\
G9 & Nahng Dum (white rice) & Chumphon \\
G10 & Hawm Jet Ban (red rice) & Krabi \\
\hline
\end{tabular}

Table 7. Description of the experimental sites.

\begin{tabular}{llll}
\hline \multirow{2}{*}{ Parameters } & \multicolumn{2}{c}{ Environments } \\
\cline { 2 - 4 } & Songkhla & Satun & Phatthalung \\
\hline Latitude & $7.13^{\circ} \mathrm{N}$ & $6^{\circ} 39^{\prime} 13^{\prime \prime} \mathrm{N}$ & $7^{\circ} 37^{\prime} 04^{\prime \prime} \mathrm{N}$ \\
Longitude & $100.26^{\circ} \mathrm{E}$ & $100^{\circ} 4^{\prime} 59^{\prime \prime} \mathrm{E}$ & $100^{\circ} 04^{\prime} 40^{\prime \prime} \mathrm{E}$ \\
Altitude $(\mathrm{m})$ & 63 & 6 & 14 \\
\hline
\end{tabular}


therefore greater yield of the genotypes in that particular environment. The Satun environment, $\mathrm{G} 8$ and $\mathrm{G} 10$ had positive IPCA1 scores and registered above average yields. G4 and G5 had negative IPCA2 values, thus the Phatthalung environment was favourable for these genotypes. Likewise, G1, G6 and G7 in the Songkhla environment had negative IPCA1 scores and thus the Songkhla environment was found to be the most favorable environment for these genotypes (Fig. 2).

\section{Materials and methods}

\section{Plant materials and conduction of experiment}

The experimental plant materials i.e., the best ten upland rice genotypes (Table 6) were selected from the report of Chuchert (2018). The experiments were carried out at the farmers' fields of Songkhla, Satun and Phatthalung Provinces under the rainfed upland conditions. Here we used a limited number of genotypes because we had to select genotypes that retained characteristics of survival under upland conditions. These genotypes were already tested under rainfed upland conditions without surface water accumulation using different experiments. Another important point was that availability of rainfed condition tolerant genotypes are limited in Thailand. The soils were tested in the soil analysis laboratory of Natural Resources Faculty, Prince of Songkla University, Hat Yai campus, Thailand with results displayed in Table 1 . The experiment was laid out with a Randomized Complete Block Design (RCBD) with three replications in each environment. Each replication consisted of four rows (5 meters per row) and ten genotypes which were randomized and replicated within each block. Each genotype was planted $30 \mathrm{~cm}$ apart between rows and $25 \mathrm{~cm}$ within the rows. Three locations differing in latitude, longitude and altitude, from sea level, are shown in Table 7 and Fig.3. 15:15:15 N-P-K fertilizers was applied at the rate of $15 \mathrm{kgs}$ of $\mathrm{N}, \mathrm{P}$ and $\mathrm{K}$ per hectare as urea, super phosphate and muriate of potash before planting. Agronomic actions, were done manually, e.g., weed and insect control. Insect pests were controlled by the application of $20 \mathrm{ml}$ per $1 \mathrm{~L}$ Cypermethrin $10 \% \mathrm{w} / \mathrm{v}$ EC and $50 \mathrm{ml}$ per $1 \mathrm{~L}$ Benfuracarb $20 \%$ $\mathrm{w} / \mathrm{v}$ EC with water. At 30 days after planting, urea fertilizer (460-0) was applied.

\section{Data collection}

Grain yield data were documented on a single plant basis using sixteen plants per genotype in each replication. At the maturity stage, data were collected and observations were recorded on the basis of plant height $(\mathrm{cm})$, number of tillers (no), number of panicles (no), panicle length $(\mathrm{cm})$, flag leaf length $(\mathrm{cm})$, flag leaf width $(\mathrm{cm})$, leaf area index, harvest index (\%), total dry weight (gm), total grain weight (gm), 1000 seed weight (gm), filled grains per panicle and unfilled grains per panicle, all of which were used to estimate grain yield per genotypes $(\mathrm{kg} / \mathrm{ha})$. The $\mathrm{G} \times \mathrm{E}$ interaction is evaluated only for yield contributing characters and grain yield per genotypes $(\mathrm{kg} / \mathrm{ha})$.

\section{Statistical analysis}

This paper mainly focused on grain yield at $12 \%$ moisture level. The grain yield of each genotype in each location was subjected to analysis of variance (ANOVA) using the R program with agricolae package (Mendiburu and Simon, 2007). Homogeneity variances were checked with $F_{\max }$ and verified homogeneous if it was less than 5 (Tabachnick and Fidell, 2001). If they were homogeneous, the quantitative trait means of the genotypes that were evaluated in all three locations were used for pooled ANOVA. The mean trait values of the 10 genotypes evaluated in three replications were subjected to statistical analysis depending on the additive part (main effect) and PCA to examine the non-additive part that remained after the ANOVA analysis (Sabaghnia et al., 2008).

\section{Additive main effect and multiplicative interaction (AMMI) method}

The AMMI method was applied with additive effects to 10 genotypes in three environments, and multiplicative was used for G×E interaction. According to Sabaghnia et al. (2008), the AMMI method at first adjusts additive effects for host genotypes and environments through the normal additive analysis of variance (ANOVA) technique and fits multiplicative effects for GXE by PCA. It affords a symbolic view of the transformed GXE interaction for any interpretation (Kempton, 1984) based on the following AMMI equation:

$Y_{g e r}=\mu+\alpha_{g}+\beta_{e}+\sum \delta_{n} \gamma_{g n} \partial_{e n}+\rho_{g e}+\varepsilon_{g e r}$

Where,

$Y_{\text {ger }}=$ Yield for genotype $\mathrm{g}$, environment e and replication $\mathrm{r}$

$\mu=$ Grand mean value for trait

$\alpha_{g}=$ Mean deviations for genotype (genotype means minus grand mean)

$\beta_{e}=$ Mean deviations for environment

$\mathrm{n}=\mathrm{PCA}$ axis number reserved in the model

$\delta_{n}=$ Singular value for PCA axis $\mathrm{n}$

$\gamma_{g n}=$ Genotype eigenvector values for PCA axis $\mathrm{n}$

$\partial_{e n}=$ Eigenvector for environment

$\rho_{g e}=$ Residuals

$\varepsilon_{\text {ger }}=$ Error is used

\section{AMMI stability value}

The AMMI stability value (ASV) catalogue has recommended for measurements and ranks genotypes according to their yield stability. Purchase et al. (2000), described the AMMI stability value (ASV) which is calculated as follows:

$$
\sqrt{\left[\frac{\text { IPCA1 Sum of square }}{\text { IPCA2 Sum of square }}(\text { IPCA1score })\right]^{2}+(\text { IPCA2score })}
$$

Where,

$\mathrm{SS}_{\text {IPCA1 }} / \mathrm{SS}_{\mathrm{IPCA} 2}$ is the weight given to the Interaction Principal Component Analysis (IPCA1) significance through allotting the IPCA1 sum of squares by the IPCA2 sum of squares. The higher 
the IPCA significance, whether negative or positive significance, the higher the explicitly adjusted genotype suits the environments. Lower ASV values, designate an additional stable genotype crosswise environment.

\section{Conclusion}

This study demonstrated statistically significant differences for environment $(E)$ and non-significant differences for genotypes (G) and for GXE interaction. In the AMMI model, the mean highest and lowest grain yield values indicated that G8 (Nahng Kian: $6234.11 \mathrm{~kg} / \mathrm{ha}$ ) and G4 (Dawk Kha: $5268.22 \mathrm{~kg} / \mathrm{ha}$ ) positioned according to the performance ranges with 8425.60 $\mathrm{kg} / \mathrm{ha}$ in Satun, to $2403.53 \mathrm{~kg} / \mathrm{ha}$ from Phatthalung. It showed $82.86 \%$, interaction followed by environment, at $1.31 \%$ to genotypic effect, and only $2.44 \%$ to GXE interaction effects. In addition, the analysis showed that low GXE interaction had high stability, which is desirable for plant breeders, farmers, and that their yields are higher, indicating the genotypes had less effect on the performance of environments. AMMI biplot of the interaction (IPCA) scores visualized $90.7 \%$ for IPCA1 and 9.3\% for IPCA2 and total scores $100 \%$ for grain yield suggesting that IPCA1 performed better with the genotypes and environments than with grain yield. The best genotypes for Satun were G8 (Nahng Kian), G10 (Hawm Jet Ban) and G2 (Mai Tahk). The Songkhla environment is suitable for G1 (Dawk Pa yawm), G6 (Khao' Trai) and G7 (Nual Hawm). Phattalung is suitable for G4 (Dawk Kha), G5 (Dawk Kahm) and G9 (Nahng Dum). According to the AMMI stability value method, the $\mathrm{G} 8$ (Nahng Kian) is the most stable for three environments.

\section{Conflict of interests}

The authors have declared no conflicts of interest.

\section{Acknowledgements}

This research work was supported by the budget (NAT610046S) of Prince of Songkla University and the Higher Education Research promotion and Thailand's Education Hub for ASEAN countries (TEH-AC) project office of the Higher Education Commission. It was partially supported by the Graduate School, and the authors thank the Field Laboratory Centre of Plant Science Department, Faculty of Natural Resources, Prince of Songkla University, Hat Yai campus, Thailand, for kindly providing the upland rice seeds.

\section{References}

Alberts M (2004) A comparison of statistical methods to describe genotype $x$ environment interaction and yield stability in multiplication maize trials. PhD Dissertation. University of the Free State, South Africa.

Amirjani MR (2011) Effect of salinity stress on growth, sugar content, pigments and enzyme activity of rice. Int J Bot. 7:7381.

Annicchiarico P, Perenzin M (1996) Adaptation patterns and definition of macro environment for selection and recommendation of common wheat. Italy J Plant Breed. 113:197-205.

Arciniegas-Alarcn S, Garcia- Pena M, Dias CTS, Krzanowski WJ (2010) An alternative methodology for imputing missing data in trials with genotype-by-environment interaction. Biom Let. 47:1-14.

Beya T, Chemeda D, Girma M, Dagnachew L, Negash G (2008) Genotype by environment interaction and grain yield stability analysis for advanced triticale (X. Triticosecale Wittmack) genotypes in Western Oromia, Ethiopia. Ethiop J Biol Sci. 7(1):45-53.

Bridhikitti A, Overcamp TJ (2011) Estimation of Southeast Asian rice paddy areas with different ecosystems from moderateresolution satellite imagery. Agric Eco and Env. 146(2012): 113-120.

Chuchert S. (2018) Genetic diversity of upland rice genotypes (Oryza sativa L.) in Thailand. PhD Dissertation. Prince of Songkla University. Thailand.

Crossa J (1990) Statistical analysis of multi-locaton trials. Adv Agron. 44:55-85.

Dingkuhn M, Luquet D, Kim HK, Tambour L, Clement Vidal A (2006) Eco meristem, a model of morphogenesis and competition among sinks in rice. 2. Simulating genotype responses to phosphorus deficiency. Func Plant Biol. 33:325337.

Ebdon JS, Gauch HG (2013) Additive main effect and multiplicative interaction analysis of national turfgrass performance trials. II. Cultivar recommendations. Crop Sci. 42:497-506.

Eberhart SA, Russell WA (1966) Stability parameters for comparing varieties. Crop Sci. 6:36-40.

Falconer DS, Mackay TFC (1996) Introduction to quantitative genetics. $\left(4^{\text {th }}\right.$ ed) Edinburgh: Longman Group Limited.

Flores F, Moreno MT, Cubero JI (1998) A comparison of univariate and multivariate methods to analyze $\mathrm{G} \times \mathrm{E}$ interaction. Field Crops Res. 56:271-286.

Freeman GH (1990) Modern statistical methods for analyzing genotype-environment interactions.p. 118-125. In: Kang MS (ed) Genotype $\times$ environment interaction and plant breeding. Louisiana State University Agricultural Center, Baton Rouge, Louisiana, USA.

Gauch HG (1988) Model selection and validation for yield trials with interaction. Int J Biom. 44:705-715.

Gauch HG, Piepho HP, Annicchaiarico P (2008) Statistical analysis of yield trials by AMMI and GGE. Further Considerations. Crop Sci. 48:866-889.

Gruneberg WJ, Manrique K, Zhang D, Hermann M (2005) Genotype $\times$ environment interactions for a diverse set of sweet potato clones evaluated across varying eco geographic conditions in peru. Crop Sci. 45:2160-2171.

Islam MR, Anisuzzaman M, Khatun $\mathrm{H}$, Sharma $\mathrm{N}$, Islam MZ, Akter A, Biswas PS (2014) AMMI analysis of yield performance and stability of rice genotypes across different Haor areas. Eco-friendly Agril J. 7 (2):20-24.

Kempton RA (1984) The use of biplots in interpreting variety by environment interaction. J Agric Sci. 103:123-135.

Lin CS, Binns MR, Lefkovitch LP (1986) Stability analysis, where do we stand. Crop Sci. 26:894. 
Manrique K, Hermann M (2002) Comparative study to determine stable performance in sweet potato (Ipomoea batatas L.) regional trials. Acta Hort. 583:87-97.

Mendiburu FD, Simon R (2007) Agricolae-a free statistical library for agricultural research. Ames, IA: lowa State University.

Messina C, Hammer G, Dong Z, Podlich D, Cooper M (2009) Modelling crop improvement in a G×ExM framework via gene-trait-phenotype relationships. In: Sadras, V.C., Calderini, D. (eds) Crop Physiology: Appl Gen Improve Agron. Elsevier, Netherlands: 235-265.

Mohammadi R, Abdulahi A, Haghparast R, Armion M (2007) Interpreting genotype-environment interactions for durum wheat grain yields using non-parametric methods. Euphytica. 157:239-251.

Naveed M, Nadeem Islam IN (2007) AMMI analysis of some upland cotton genotypes for yield. World J Agric Sci. 3(1):3944.

Purchase JL, Hatting H, Van Deventer CS (2000) Genotype environment interaction of winter wheat (Triticum aestivum L.). S Afr J Plant Soil. 17:101-107.

Rodrigues PC, Malosetti M, Gauch HG, Van Eeuwijk FA (2014) A weighted AMMI algorithm to study genotype-by- environment interaction and QTL-by-environment interaction. Crop Sci. 54:1-16.

Sabaghnia N, Sabaghpour SH, Dehghani H (2008) The use of an AMMI model and its parameters to analyse yield stability in multi environment trials. J Agric Sci. 146(5):571-581.

Tabachnick BG, Fidell LS (2001) Using Multivariate Statistics. 4th edn, Allyn and Bacon, Boston.

Thillainathan M, Fernandez GC (2001) SAS applications for Tai's stability analysis and AMMI model in genotype $x$ environment interaction (GEI) effects. J Hered. 92(4):367371.

Yaghotipoor A, Farshadfar E (2007) Non-parametric estimation and component analysis of phenotypic stability in chickpea (Cicer arietinum L.). Pak J Biol Sci. 10:2646-2652.

Yan W, Hunt LA (2001) Interpretation of genotypeenvironment interaction for winter wheat yield in Ontario. Crop Sci. 41:19-25.

Yang RC, Crossa J, Cornelius PL, Burgueno J (2009) Biplot analysis of genotype $\times$ environment interaction: Proceed with caution. Crop Sci. 49:1564-1576.

Zulqarnain, Akhter M, Mahmood A, Khan R (2017) Comparison of GGE biplot and AMMI analysis of multi-environment trial (MET) data to assess adaptability and stability of rice genotypes. Afr J Agric Res. 12(51):3542-3548. 